\title{
The effect of subglottic secretion drainage on the incidence of ventilator associated pneumonia
}

\author{
Marta Walaszek ${ }^{\mathrm{a}, \mathrm{c}}$, Agnieszka Gniadek ${ }^{\mathrm{b}}$, Malgorzata Kolpac, Zdzislaw Wolakc, Alicja Kosiarskac
}

Background. Ventilator-Associated Pneumonia (VAP) is an undesired side effect of mechanical ventilation in intensive care units (ICUs).

Aim. We evaluated whether endotracheal tubes with subglottic secretion drainage (SSD) would reduce the incidence of VAP among patients undergoing mechanical ventilation in an ICU.

Methods. The analysis of medical records of patients undergoing mechanical ventilation exceeding $48 \mathrm{~h}$ who were hospitalised in ICUs between 2007 and 2014 led to separating two groups of patients: those in whom no subglottic drainage was applied (NSSD) (records dating from 2007-2010) and those whose treatment involved endotracheal tubes with subglottic secretion drainage (SSD) (records dating from 2011-2014).

Results. Analysis of 1807 patients hospitalised in ICUs (804 NSSD patients and 1003 SSD patients). A difference was found in the frequency of VAP incidence between the groups $(P<0.001)$. In the NSSD group as many as 84 cases were reported (incidence: 10.7\%), and in the SSD group - 43 cases (incidence: $5.2 \%)$. The odds ratio (OR) and relative risk (RR) was 2.5. The probability of VAP was significantly higher in the NSSD group. The risk factors of VAP incidence $(P<0.001)$ included the correlation between reintubation $(R=0.271)$, tracheostomy $(R=0.309)$ and bronchoscopy $(R=0.316)$.

Conclusion. Use of endotracheal tubes with subglottic secretion drainage in patients in the ICU on mechanical ventilation significantly reduced the incidence of VAP.

Key words: ventilator-associated pneumonia (VAP), subglottic secretion drainage (SSD), endotracheal tube (ETT)

Received: May 7, 2017; Accepted: September 12, 2017; Available online: October 17, 2017

https://doi.org/10.5507/bp.2017.041

${ }^{a}$ Sw. Lukasz Provincial Hospital in Tarnow, Poland

${ }^{b}$ Department of Nursing Management and Epidemiology Nursing, Faculty of Health Sciences, Jagiellonian University Medical College, Cracow, Poland

'Department of Nursing, Institute of Health Sciences, State Higher Vocational School in Tarnow, Poland Corresponding author Marta Walaszek, e-mail:zak@lukasz.med.pl

\section{INTRODUCTION}

It is typical in intensive care units to apply advanced treatment techniques, which include invasive monitoring and mechanical support of vital functions in cases of organ or system failure. The most frequently applied therapeutic procedures in intensive care units are intubation and tracheostomy, which allow for mechanical ventilation ${ }^{1}$. Numerous scientific societies and associations, such as the American Thoracic Society/Infectious Diseases Society of America (ATS/IDSA), Centers for Disease Control (CDC), and the American Association of Critical-Care Nurses (AACN), recommend the application of Subglottic Secretion Drainage (SSD) in order to limit the risk of developing Ventilator - Associated Pneumonia (VAP) by means of draining the secretion remaining over the sealing cuff. The tubes need frequent cleaning as they often get blocked, especially the draining duct. This may be the reason why they are not commonly applied $^{2,3}$,

VAP infections in intensive care units are a phenomenon with a range of health issues. They are the reason behind prolonged hospitalisation, increased mortality and significant increase in treatment costs ${ }^{4,5}$. According to the literature, $20-50 \%$ of all hospital infections are developed in ICUs, with a significant portion of those consisting of VAP infections ${ }^{6-9}$. Increased risk of infection development in ICU patients is associated with the necessity to use invasive procedures, the aim of which is to support ineffective systems ${ }^{10,11}$. In VAP prevention, the importance of the types of endotracheal tubes (ETT) and cuff pressure monitoring is emphasized ${ }^{12,13}$.

According to the studies of European supervision European Centre for Disease Prevention and Control (ECDC) 2011-2012 - the incidence density rate for VAP in ICUs is 10.5 per 1000 days of intubation. In the annual ECDC epidemiological report of 2014, pneumonia was found in $5.3 \%$, of which $93 \%$ was related to intubated patients, and the incidence density rate associated with VAP was 10.1 per 1000 days of intubation ${ }^{14,15}$. In Poland, the incidence density rate for VAP reaches between 10.2 and 16.5 per 1000 days of mechanical ventilation ${ }^{8,9,16}$.

The research was aimed at evaluating the effect which the application of endotracheal tubes with SSD would have on the incidence of VAP among patients undergoing mechanical ventilation. 


\section{MATERIALS AND METHODS}

The study involved a retrospective analysis of patients undergoing mechanical ventilation lasting more than $48 \mathrm{~h}$, who were hospitalised in Św. Łukasz Provincial Hospital in Tarnów between 2007 and 2014. The patients were observed in two separate groups: the first group consisted of patients hospitalised between 2007 and 2010 in whose cases subglottic secretion drainage was not applied; No Subglottic Secretion Drainage Group (NSSD), and the second group hospitalised between 2011 and 2014 consisted of patients whose treatment involved endotracheal tubes with SSD. The intubation tube, with subglottic suctioning capability, was placed in each patient in whom the necessity to perform mechanical ventilation for over 2 days was expected, as well as in those in the case of whom the score according to the American Society of Anesthesiology (ASA) scale exceeded 3 points. Patients who did not meet the criteria described above were excluded from the study.

The research methods included analysis of the medical records of the patients undergoing mechanical ventilation who were hospitalised in the ICU wards of Św. Lukasz Provincial Hospital in Tarnów.

Preventive measures defined by standard treatment procedures were applied in the examined hospital ward before the research started in 2007 and also during the research. They included: patients' reclining position, disposable intubation tubes if required, application of open system of airway secretion drainage, tubes with polyurethane cuffs, sustaining the cuff pressure at $20-30 \mathrm{~cm} \mathrm{H}_{2} \mathrm{O}$, disposable heat and moisture exchanges (HME) which were close-coupled with antibacterial filters in the respirator tube system. Intubation tubes were removed only when necessary, meaning a situation of unexpected gradual narrowing of the tube lumen until its complete closure. The consistency of the application of the preventive measures mentioned above was systematically supervised by monitoring the amount of materials used and confirmed by appropriate documents. In the case of any suspicion of VAP infection the patients had microbiological tests done. The material for microbiological tests was collected from the respiratory tract by means of bronchoalveolar lavage (BAL), a brush, trachea aspirate or, alternatively, a qualitative culture of the patient's sputum was examined. Cases of VAP were detected by means of active methods by the Infection Control Unit cooperating with ICU staff. Information about patients' treatment was obtained from the electronic data base in the InfoMedica hospital system. VAP was diagnosed following the definitions created by CDC as well as ECDC (European Centre for Disease Prevention and Control) taking into account microbiological diagnosis for hospital-acquired pneumonia (HAP) (ref. ${ }^{17-19}$ ).

In order to carry out the evaluation of the epidemiological situation the following epidemiological indica- tors were applied: VAPs cumulative incidence (number of ventilator-associated pneumonia episodes / number of patients x 100); VAPs / 1000 patient days (number of ventilator-associated pneumonias episodes / number of patient days x 1000; VAPs incidence density (number of ventilator-associated pneumonias episodes / number of ventilator-days x 1000); VAPs mortality (\% death of VAPs=number of deaths caused by ventilator-associated pneumonias/number of ventilator-associated pneumonias x 100); Device-associated rates and device utilization $(\mathrm{DU}$ ratio $=$ number of ventilator-days $/$ number of patient-days).

Permission to conduct the study was obtained from the Director of Św. Łukasz Hospital in Tarnów, and all analyses of medical documentation were performed according to ethical standards and the principles of the Declaration of Helsinki.

The statistical analysis of collected material used IBM SPSS STATISTICS (SPSS - Statistical Package for the Social Sciences) statistical software, and Microsoft Excel from Microsoft. The description of the entire study population was prepared using basic statistical parameters. In the case of features of ordinal or dichotomous character, the information about the number and percentage share of specific variants was used. For calculating the measure of the relation between risk exposure and VAP development, odds ratio (OR) and relative risk (RR) were used, determining the probability ratio for event occurrence in comparable groups. In order to establish which of the relations were statistically significant, a number of statistical tests were used $(P)$ including the chi-squared test $\left(\chi^{2}\right)$ and Spearman's rank correlation coefficient (R).

\section{RESULTS}

1807 patients took part in the research between 2007 and 2014. There were 804 patients in the "no subglottic secretion drainage" group and 1003 patients in the "subglottic secretion drainage" one. A difference was observed in VAP incidence frequency between both groups $(P<0.001)$. In the NSSD group 86 VAP cases were reported (cumulative incidence $10.7 \%$ ), whereas in the SSD group, in which the tubes with subglottic secretion drainage were applied, there were only 43 VAP cases (4.3\%). The odds ratio (OR) and relative risk (RR) was to 2.5 , which meant that the probability of VAP cumulative incidence was higher in the NSSD group. The mortality rate was similar $-33.7 \%$ and $37.2 \%$ (Table 1 ).

The average age of hospitalized patients was 56 in the NSSD group and 59 in the SSD group. VAP infections were more common in men than in women, however the difference was not statistically significant. In the group in which subglottal drainage was not applied as many as 60 VAP cases were reported (cumulative incidence $14 \%$ ) vs 26 cases $(9 \%)$ in SDD group. In all age categories VAP incidence was higher in the NSSD group and lower in the SSD one. A statistically significant determinant of VAP cumulative incidence $(P<0.001)$ was the situation when 
Table1. Comparison of the number of patients, patient-days of hospitalisation, numbers of VAP incidence, cumulative incidence, incidence density, mortality rate in "no subglottic secretion drainage group" (NSSD) and "subglottic secretion drainage group" (SSD) with mechanical ventilation.

\begin{tabular}{|c|c|c|c|c|c|c|c|c|c|c|c|}
\hline 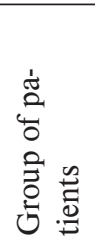 & 坖 & 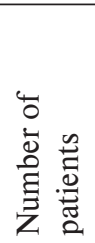 & 苞 & 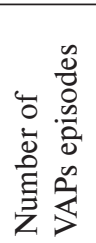 & 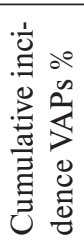 & 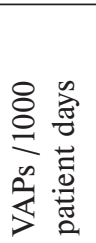 & 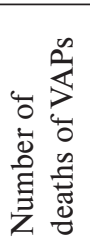 & 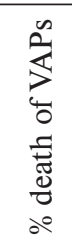 & 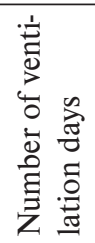 & 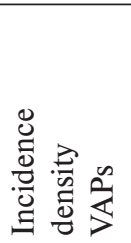 & 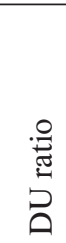 \\
\hline NSSD & $2007-2010$ & 804 & 7577 & 86 & 10.7 & 11.4 & 29 & 33.7 & 4542 & 18.9 & 0.60 \\
\hline SSD & 2011-2014 & 1003 & 6873 & 43 & 4.3 & 6.3 & 16 & 37.2 & 4720 & 9.1 & 0.69 \\
\hline Total & 2007-2014 & 1807 & 14450 & 129 & 7.5 & 8.9 & 45 & 35.5 & 9262 & 14.0 & 0.63 \\
\hline
\end{tabular}

NSSD - No subglottic secretion drainage, SSD - subglottic secretion drainage, VAP - ventilator-associated pneumonia, DU ratio - number of ventilator-days / number of patient-days

Table 2. Comparison of mechanically ventilated patients by sex, age and the time of mechanical ventilation with a division into "no subglottic secretion drainage" (NSSD) and "subglottic secretion drainage" (SSD) groups.

\begin{tabular}{|c|c|c|c|c|c|c|c|}
\hline \multicolumn{4}{|c|}{$\begin{array}{c}\text { NSSD } \\
2007-2010\end{array}$} & \multicolumn{4}{|c|}{$\begin{array}{c}\text { SSD } \\
2011-2014\end{array}$} \\
\hline $\begin{array}{c}\text { Factor } \\
\text { category }\end{array}$ & $\begin{array}{c}\text { Number } \\
\text { of patients } \\
\text { without VAP }\end{array}$ & $\begin{array}{c}\text { Number of } \\
\text { patients with } \\
\text { VAP }\end{array}$ & $\begin{array}{l}\text { Cumulative } \\
\text { incidence } \\
\text { VAPs \% }\end{array}$ & $\begin{array}{c}\text { Factor } \\
\text { category }\end{array}$ & $\begin{array}{c}\text { Number } \\
\text { of patients } \\
\text { without VAP }\end{array}$ & $\begin{array}{c}\text { Number of } \\
\text { patients with } \\
\text { VAP }\end{array}$ & $\begin{array}{c}\text { Cumulative } \\
\text { incidence } \\
\text { VAPs \% }\end{array}$ \\
\hline \multicolumn{8}{|l|}{ Sex } \\
\hline M & 429 & 60 & 14.0 & M & 554 & 29 & 5.2 \\
\hline $\mathrm{F}$ & 289 & 26 & 9.0 & $\mathrm{~F}$ & 406 & 14 & 3.4 \\
\hline \multicolumn{4}{|c|}{$\chi^{2}(\mathrm{n}=804, \mathrm{df}=1)=3.234 P=0.072$} & \multicolumn{4}{|c|}{$\chi^{2}(\mathrm{n}=1003, \mathrm{df}=1)=0.943 \quad P=0.331$} \\
\hline \multicolumn{8}{|l|}{ age (years) } \\
\hline $1-18$ & 42 & 2 & 4.8 & 18-sty & 36 & 1 & 2.8 \\
\hline $19-30$ & 61 & 11 & 18.0 & $19-30$ & 67 & 1 & 1.5 \\
\hline $31-50$ & 158 & 21 & 13.3 & $31-50$ & 161 & 9 & 5.6 \\
\hline $51-75$ & 293 & 41 & 14.0 & $51-75$ & 482 & 23 & 4.8 \\
\hline$>75$ & 164 & 11 & 6.7 & $>75$ & 214 & 9 & 4.2 \\
\hline \multicolumn{4}{|c|}{$\chi^{2}(\mathrm{n}=804, \mathrm{df}=4)=7.873 \quad P=0.960$} & \multicolumn{4}{|c|}{$\chi^{2}(\mathrm{n}=1003, \mathrm{df}=4)=1.769 P=0.778$} \\
\hline \multicolumn{8}{|c|}{ time of mechanical ventilation (days) } \\
\hline $1-5$ & 405 & 4 & 1.0 & 05-sty & 529 & 2 & 0.4 \\
\hline $6-10$ & 179 & 8 & 4.5 & 10-cze & 254 & 7 & 2.8 \\
\hline $11-20$ & 75 & 20 & 26.7 & $11-20$ & 129 & 11 & 8.5 \\
\hline$>20$ & 59 & 54 & 91.5 & $>20$ & 48 & 23 & 47.9 \\
\hline \multicolumn{4}{|c|}{$\chi^{2}(\mathrm{n}=804, \mathrm{df}=4)=224.3 \quad P<0.001$} & \multicolumn{4}{|c|}{$\chi^{2}(\mathrm{n}=1003, \mathrm{df}=3)=140.1 \quad P<0.001$} \\
\hline
\end{tabular}

NSSD - No subglottic secretion drainage, SSD - subglottic secretion drainage, n - number of patients, $P$ - significance level, $\mathrm{M}$ - men, F - women, VAP - ventilator-associated pneumonia, $\chi^{2}$ - chi-square independence test

the time spent on the ward exceeded 20 days. Among the patients with mechanical ventilation and hospitalized longer than 20 days the VAP cumulative incidence was the highest in both groups and amounted to 54 cases in the NSSD group (cumulative incidence $91.5 \%$ ) vs 23 cases in the SSD group (47.9\%) (Table 2).

Both in the NSSD and the SSD group VAP infections were most frequent in patients whose primary reason for hospital admission included multiple organ trauma, respiratory system disease and central nervous system disease. Other diseases which were the reason for patients' hospitalization were also analyzed (Table 3). Statistically significant treatment-associated risk factors for developing VAP $(P<0.001)$ which proved to be statistically moderately correlated included the correlation between reintubation $(\mathrm{R}=0.271)$, tracheostomy $(\mathrm{R}=0.309)$ and bronchoscopy $(\mathrm{R}=0.316)$. Average positive correlation means that the performance of invasive procedures in a patient, such as: tracheostomy, reintubation and bronchoscopy increases the risk of VAP development (Table 4).

The most frequent etiological factors were Acinetobacter baumannii (69 isolates, i.e. 44.2\%), Pseudomonas aerugi- 
Table 3. Independent factors of VAP presence related to the patient and his/her primary disease (the reason for hospital ICU admission) with a division into "no subglottic secretion drainage" (NSSD) and "subglottic secretion drainage" (SSD) groups.

\begin{tabular}{|c|c|c|c|c|c|c|}
\hline \multirow{2}{*}{$\begin{array}{l}\text { VAP risk factors related to the } \\
\text { patient's primary disease (the } \\
\text { disease diagnosed on the day } \\
\text { of the patient's hospital ICU } \\
\text { admission) }\end{array}$} & & $\begin{array}{c}\text { NSSD } \\
2007-2010 \\
(n=804)\end{array}$ & & & $\begin{array}{c}\text { SSD } \\
2011-2014 \\
(n=1003)\end{array}$ & \\
\hline & $\begin{array}{l}\text { Number of } \\
\text { hospitalisa- } \\
\text { tions }\end{array}$ & $\begin{array}{c}\text { Number of } \\
\text { patients with } \\
\text { VAP }\end{array}$ & $\begin{array}{l}\text { Cumulative } \\
\text { incidence } \\
\text { VAPs }\end{array}$ & $\begin{array}{l}\text { Number of } \\
\text { hospitalisa- } \\
\text { tions }\end{array}$ & $\begin{array}{c}\text { Number of } \\
\text { patients with } \\
\text { VAP }\end{array}$ & $\begin{array}{c}\text { Cumulative } \\
\text { incidence } \\
\text { VAPs }\end{array}$ \\
\hline Multiple organ trauma & 117 & 17 & 14.5 & 128 & 6 & 4.7 \\
\hline Endocrine system & 9 & 1 & 11.1 & 134 & 4 & 3.0 \\
\hline Central nervous system & 188 & 29 & 15.4 & 103 & 9 & 8.7 \\
\hline Respiratory system & 135 & 21 & 15.6 & 176 & 16 & 9.1 \\
\hline Digestive system & 93 & 3 & 3.2 & 41 & 1 & 2.4 \\
\hline Food poisoning & 26 & 2 & 7.7 & 119 & 5 & 4.2 \\
\hline Sepsis & 11 & 3 & 27.3 & 26 & 3 & 11.5 \\
\hline Cardiology & 105 & 6 & 5.7 & 140 & 2 & 1.4 \\
\hline Musculoskeletal system & 9 & 1 & 11.1 & 45 & 1 & 2.2 \\
\hline Others & 20 & 2 & 10.0 & 27 & 1 & 3.7 \\
\hline Tumour & 51 & 1 & 2.0 & 58 & 0 & 0.0 \\
\hline Genitourinary system & 40 & 0 & 0.0 & 6 & 0 & 0.0 \\
\hline
\end{tabular}

NSSD - No subglottic secretion drainage, SSD - subglottic secretion drainage,

Table 4. Independent factors of VAP presence related to the treatment applied on ICU with a division into "no subglottic secretion drainage" (NSSD) and "subglottic secretion drainage" (SSD) groups.

\begin{tabular}{|c|c|c|c|c|}
\hline \multirow[t]{2}{*}{ VAP risk factors } & \multicolumn{2}{|c|}{$\begin{array}{c}\text { NSSD } \\
2007-2010 \\
(\mathrm{n}=804)\end{array}$} & \multicolumn{2}{|c|}{$\begin{array}{c}\text { SSD } \\
2011-2014 \\
(\mathrm{n}=1003)\end{array}$} \\
\hline & $P$ & $\mathrm{R}$ & $P$ & $\mathrm{R}$ \\
\hline Reintubation & $P<0.001$ & 0.27 & $P<0.001$ & 0.26 \\
\hline Bronchoscopy & $P<0.001$ & 0.32 & $P<0.001$ & 0.30 \\
\hline Tracheostomy & $P<0.001$ & 0.29 & $P<0.001$ & 0.26 \\
\hline Unconscious patient & $P<0.001$ & 0.10 & $P<0.001$ & 0.10 \\
\hline Intubation & $P<0.001$ & 0.13 & $P<0.001$ & 0.12 \\
\hline Probe & $P<0.001$ & 0.13 & $P<0.001$ & 0.13 \\
\hline Analgosedation & $P<0.001$ & 0.11 & $P<0.001$ & 0.11 \\
\hline Enteral nutrition & $P<0.001$ & 0.15 & $P<0.001$ & 0.14 \\
\hline Wounds and bedsores & $P<0.001$ & 0.11 & $P<0.001$ & 0.11 \\
\hline Diabetes & $P=0.013$ & 0.08 & $P=0.027$ & 0.07 \\
\hline Central vein catheter & $P=0.389$ & 0.03 & $P=0.499$ & 0.02 \\
\hline Paralysis & $P=0.037$ & 0.06 & $P=0.068$ & 0.06 \\
\hline Chest drainage & $P=0.039$ & 0.08 & $P=0.055$ & 0.09 \\
\hline Parenteral nutrition & $P=0.092$ & 0.06 & $P=0.102$ & 0.06 \\
\hline
\end{tabular}

NSSD - No subglottic secretion drainage, SSD - subglottic secretion drainage, $P$ - significance level of Chi-square test of independence for VAP, $\mathrm{R}=$ Spearman's rank correlation coefficient 
Table 5. Etiological factors of VAP incidence in the examined groups: "no subglottic secretion drainage" (NSSD) and "subglottic secretion drainage" (SSD).

\begin{tabular}{|c|c|c|c|c|}
\hline \multirow[b]{2}{*}{ VAP etiological factors } & \multicolumn{2}{|c|}{$\begin{array}{c}\text { NSSD } \\
2007-2010\end{array}$} & \multicolumn{2}{|c|}{$\begin{array}{c}\text { SSD } \\
2011-2014\end{array}$} \\
\hline & $\begin{array}{l}\text { Number of micro- } \\
\text { organisms in VAP }\end{array}$ & $\begin{array}{c}\% \text { of the total } \\
\text { number of } \\
\text { microorganisms in } \\
\text { VAP }\end{array}$ & $\begin{array}{c}\text { Number } \\
\text { of microorganisms } \\
\text { in VAP }\end{array}$ & $\begin{array}{l}\% \text { of the total } \\
\text { number of } \\
\text { microorganisms } \\
\text { in VAP }\end{array}$ \\
\hline Acinetobacter baumannii & 39 & 45.3 & 22 & 45.8 \\
\hline Pseudomonas aeruginosa & 5 & 5.8 & 10 & 20.8 \\
\hline Escherichia coli & 8 & 9.3 & 5 & 10.4 \\
\hline Klebsiella pneumoniae & 2 & 2.3 & 3 & 6.3 \\
\hline Klebsiella pneumoniae ESBL (+) & 1 & 1.2 & 0 & 0.0 \\
\hline Staphylococcus aureus & 4 & 4.7 & 1 & 2.1 \\
\hline Staphylococcus aureus MRSA & 2 & 2.3 & 0 & 0.0 \\
\hline Candida albicans & 5 & 5.8 & 1 & 2.1 \\
\hline Proteus mirabillis & 3 & 3.5 & 2 & 4.2 \\
\hline Enterobacter cloace & 0 & 0.0 & 1 & 2.1 \\
\hline Enterococcus faecium & 0 & 0.0 & 1 & 2.1 \\
\hline Kliebsiella oxytoca & 0 & 0.0 & 1 & 2.1 \\
\hline Morganella morgannii & 2 & 2.3 & 0 & 0.0 \\
\hline Citrobacter freundii & 0 & 0.0 & 1 & 2.1 \\
\hline Proteus vulgaris & 3 & 3.5 & 0 & 0.0 \\
\hline Streptococcus pneumoniae & 1 & 1.2 & 0 & 0.0 \\
\hline Haemophilus influenzae & 1 & 1.2 & 0 & 0.0 \\
\hline Not isolated & 10 & 11.6 & 0 & 0.0 \\
\hline Total & 86 & 100.0 & 48 & 100.0 \\
\hline
\end{tabular}

NSSD - No subglottic secretion drainage, SSD - subglottic secretion drainage, MR - methicyllin-resistant staphylococcus aureus, ESBL (+) extended-spectrum beta-lactamases

nosa and Escherichia coli. Acinetobacter baumannii, which is dominant in the etiology of VAP, proved to be $96 \%$ resistant to carbapenems and two other groups of medicines, and in the case of Pseudomonas aeruginosa the resistance applied to $100 \%$ of isolates (Table 5).

\section{DISCUSSION}

Both medical objectives and patients' comfort can be achieved by applying proper care based on "SMART" strategy: Specific, Measurable, Achievable, Realistic, Timely. Therefore, in the case of providing proper care of respiratory system of patients undergoing mechanical ventilation it is advisable to apply such methods which reduce the frequency of complications and can be applied easily and quickly. Thus, evidence-based medicine (EBM) plays an important role in the optimal choice of methods which allow for minimization of the risk of complications.

VAP infections in ICUs may be the reason for prolonged hospitalisation, increased mortality rate and a significant increase in the costs of treatment ${ }^{4,5}$. Scientific publications point out that as much as $20-50 \%$ of all hospital infections originate in ICUs, and VAP makes up a large percentage of them ${ }^{6,8,20}$. Therefore, replacing traditional methods by application of endotracheal tubes subglottic secretion drainage may be a significant factor which would reduce the risk of complications including infections.

According to research carried out in 2011-2012 by the ECDC, the indicator of VAP incidence density in ICUs reached 10.5 for 1000 days of intubation ${ }^{20}$. The annual epidemiological report prepared by the ECDC in 2014 pointed out that pneumonia was detected in 5\% of patients, 93\% of whom were intubated, and the VAP incidence density reached 10.1 for 1000 days of intubation ${ }^{8}$. In Poland VAP incidence density ranges between 10.2 and 16.5 for 1000 days of mechanical ventilation ${ }^{8,9,16}$.

In the population of 1807 patients examined during the research in the ICU of Św. Łukasz Provincial Hospital in Tarnów, VAP incidence reached $8 \%$ (the figures differed for specific groups: NSSD - $11 \%$ vs SSD - 4\%), and the incidence density quotient reached 14 for 1000 days of mechanical ventilation (NSSD group - 18.9 vs SSD group 9.1). Following the analysis of microbiological flora which was responsible for the incidence of hospital pneumonia the conclusion can be drawn that the dominant microorganism found in the material examined which accounts for VAP incidence was Acinetobacter baumannii, and then Pseudomonas aeruginosa. According to the ECDC. Pseudomonas aeruginosa was the most frequently isolated microorganism ${ }^{15}$.

In the research carried out in the ICU of Św. Łukasz Provincial Hospital in Tarnów a 50\% decrease in the number of VAP infections was reported in the group 
of patients in whom subglottic secretion drainage was applied compared to the group without subglottic secretion drainage (SSD - 43 cases, i.e. $4 \%$ vs NSSD - 86 cases, i.e. $11 \%)$. The application of endotracheal tubes subglottic secretion drainage as a VAP preventive measure was the subject of previous research ${ }^{21-23}$. In the meta-analysis carried out by Muscedere and others in 2011, which included 2242 patients and dealt with the problem of subglottic secretion drainage, both continuous and intermittent suction was found to reduce VAP incidence rate by $50 \%$ (ref. ${ }^{24}$ ). Moreover, ICU hospitalization time was shortened by 1.5 days, as well as the time of mechanical ventilation. Meta-analysis of 10 randomized controlled trials ( 2213 patients) carried out in 2012 by Wang et al. also showed a $44 \%$ decline in the vulnerability to VAP (ref. ${ }^{25}$ ). Dezfuliani et al. in their meta-analysis of 5 randomized controlled trials from 2005 also discovered positive effects of the application of subglottic secretion drainage ${ }^{23}$. Hospitalisation time and mortality rate were comparable in both groups. The results obtained in Św. Lukasz Provincial Hospital in Tarnów and based on the analysis of 1807 patients treated there, confirm the observations of the aforementioned authors. In some publications authors point out the higher efficiency of subglottic secretion drainage among patients whose treatment involves a long time of mechanical ventilation ${ }^{2}$. Mujica-Lopez et al. emphasize that the diameter of a suction catheter in endotracheal tubes affects the suction efficiency and cause blockages ${ }^{26}$. Other research implies that the high efficiency of the application of endotracheal tubes with subglottic secretion drainage in VAP prevention might be influenced by other factors, such as particle structure of the secretion, suction force, or the type of material from which the sealing cuff is produced ${ }^{27-29}$.

The cause of patient hospitalisation may be an independent risk factor of VAP development. Multiple organ trauma is the most frequent cause of hospitalisations in ICUs. In studies conducted by Różańska et al. the VAP incidence among patients with trauma was $29 \%$ (ref. ${ }^{30}$ ). In another study, VAP incidence in trauma was $9 \%$ (ref. $^{31}$ ). In this study, VAP incidence in patients admitted to ICUs with multiple trauma was $15 \%$ in NSSD patients, with a subsequent decrease in incidence in SSD to $5 \%$.

Risk factors related to invasive diagnostic and treatment methods may contribute to VAP development. In this study, tracheostomy, reintubation and bronchoscopy were more often performed in patients with VAP and increase in intervention frequency was positively correlated with VAP incidence.

\section{CONCLUSION}

Use of endotracheal tubes with subglottic secretion drainage in patients from an ICU ward significantly reduced the incidence of VAP.

The time of mechanical ventilation was shorter in the patients with subglottic secretion drainage but the mortality rate was comparable for both groups. The results need to be tested further.

\section{ABBREVIATIONS}

AACN, American Association of Critical-Care Nurses; ASA, American Society of Anesthesiology; ATS/ IDSA, American Thoracic Society/Infectious Diseases Society of America; BAL, Bronchoalveolar Lavage; CDC, Centers for Disease Control; EBM, EvidenceBased Medicine; ECDC, European Centre for Disease Prevention and Control; ETT, Endotracheal Tube; HAP, Hospital-Acquired Pneumonia; HME, Heat and Moisture Exchanges; ICU, Intensive Care Unit; NSSD, No subglottic Secretion Drainage Group; SSD, Subglottic Secretion Drainage; VAP, Ventilator-Associated Pneumonia;

Author contributions: MW, AG, MK, AK: manuscript writing; MW, AK: study design; MW, AG, AK: analysis and interpretation of data; MW, MK, ZW: drafting the manuscript and revising it critically for important intellectual content; MW, AG, MK, ZW: agreed to be accountable for all aspects of the work in ensuring that queries relating to the accuracy and integrity of the work are appropriately investigated and resolved; $\mathrm{MW}, \mathrm{AG}, \mathrm{MK}, \mathrm{ZW}$ : final approval.

Conflict of interest statement: None declared.

\section{REFERENCES}

1. Kallet $\mathrm{RH}$. The Vexing Problem of Ventilator-Associated Pneumonia: Observations on Pathophysiology, Public Policy, and Clinical Science. Respir Care 2015;60(10):1495-508.

2. Klompas M. Prevention of ventilator-associated pneumonia. Expert Rev Anti Infect Ther 2010;8(7):791-800.

3. Bonten MJ. Healthcare epidemiology: Ventilator-associated pneumonia: preventing the inevitable. Clin Infect Dis 2011;52(1):115-21.

4. Vincent JL, Bihari DJ, Suter PM, Buining HA, White J, Nicolas Chanoin MA, Wolff M, Spencer RC, Hemmer M. The prevalence of nosocomial infection in intensive care unit in Europe. Results of European prevalence of infection in intensive care (EPIC) study. EPIC International Advisory Committee. JAMA 1995;274(8):639-44.

5. Pileggi C, Bianco A, Flotta D, Nobile CG, Pavia M. Prevention of ventilator-associated pneumonia, mortality and all intensive care unit acquired infections by topically applied antimicrobial or antiseptic agents: a meta-analysis of randomized controlled trials in intensive care units. Crit Care 2011;15(3):R115.

6. Gaszyński W. Zakażenia szpitalne w oddziale intensywnej terapii [w] Zakażenia szpitalne w wybranych oddziałach cz.Il pod red. Denys A. 2013:257-302.

7. Mahmoodpoor A, Nader ND. The use of Taperguard endotracheal tubes and intermittent subglottic suctioning in reducing the frequency of ventilator-associated pneumonia. J Crit Care 2017;39:292.

8. Rutkowska K, Przybyła M, Misiołek H. Healthcare associated infection In the newly-opened intesive care unit. Anaesthesiol Intensive Ther 2013;45(2):62-6.

9. Duszyńska W, Rosenthal VD, Dragan B, Węgrzyn P, Mazur A, Wojtyra P. et al. Ventilator - associated pneumonia monitoring according to the INICC Project at one Centre. Anaesthesiol Intensive Ther 2015:47(1):34-9.

10. Błaszczyk M, Tomczak H, Gordon M, Błażejewska W. Funkcjonalna przyszłość oddziałów intensywnej terapii - zakażenia i antybiotyki: Anestezjologia i Ratownictwo 2012;6:141-50.

11. Guidelines for the Management of Adults with Hospital-acquired, Ventilator-associated, and Healthcare-associated Pneumonia. Am J Respir Crit Care Med 2005;171(4):388-416.

12. Akdogan O, Ersoy Y, Kuzucu C, Gedik E, Togal T, Yetkin F. Assessment of the effectiveness of a ventilator associated pneumonia prevention bundle that contains endotracheal tube with subglottic drainage and cuff pressure monitorization. Braz J Infect Dis;21(3):276-81. 
13. Li Bassi G, Senussi T, Aguilera Xiol E. Prevention of ventilator-associated pneumonia. Curr Opin Infect Dis 2017;30(2):214-20.

14. European Centre for Disease Prevention and Control. Annual Epidemiological Report 2013. Reporting on 2011 surveillance data and 2012 epidemic intelligence data. Stockholm: ECDC; 2013 Available from http://ecdc.europa.eu/en/publications/Publications/ Annual-Epidemiological-Report-2013.pdf. (accessed on 6.6.2017).

15. European Centre for Disease Prevention and Control. Annual epidemiological report 2014. Antimicrobial resistance and healthcareassociated infections. Stockholm: ECDC; 2015. Available from: http:/ ecdc.europa.eu/en/publications/Publications/antimicrobial-resistance-annual-epidemiological-report.pdf. (accessed on 6.6.2017).

16. Wałaszek M, Wolak Z, Dobroś W. Zakażenia szpitalne u pacjentów hospitalizowanych w latach 2005-2011. Szpital Wojewódzki im. Św. Łukasza w Tarnowie. Przegl Epidemiol 2012;66(3):617-21.

17. CDC/NHSN Surveillance Definition of Healthcare - Associated Infection and Criteria for Specific Types of Infections in the Acute Care Setting. Available from: www.cdc.gov (accessed on 8.8.2015).

18. European Center for Disease Prevention and Control. Point prevalence survey of healthcare - associated infections and antimicrobial use in European acute care hospitals - protocol version 4.3. Stockholm: ECDC; 2012. Available from: http://www.ecdc.europa eu/en/publications/publications/0512-ted-pps-hai-antimicrobialuse-protocol.pdf.website (accessed on 8.7.2015).

19. European Centre for Disease Prevention and Control. European surveillance of Healthcare associated infections in intensive care units - HAI-Net ICU protocol, version 1.02. Stockholm: ECDC; 2015 Available from: http://www.ecdc.europa. (accessed on 24.04.2015).

20. Hryniewicz W, Kusza K, Ozorowski T, Fliescher M, Kaczur -Misiewska A, Trejnowska E. et al. Strategia lekooporności w OIT. Narodowy Program Ochrony Antybiotyków na lata 2011-2015.

21. Lacherade J, De Jonghe B, Guezennec P, Debbat K, Hayon J, Monsel A, Fangio P, Appere de Vecchi C, Ramaut C, Outin H, Bastuji-Garin $S$. Intermittent subglottic secretion drainage and ventilator-associated pneumonia: a multicenter trial, Am J Respir Crit Care Med 2010;182(7):910-7.
22. Smulders K, van der Hoeven H, Weers-Pothoff I, VandenbrouckeGrauls C. A randomized clinical trial of intermittent subglottic secretion drainage in patients receiving mechanical ventilation. Chest 2002;121(3):858-62.

23. Delfuzian C, Shojania K, Collard H, Kim HM, Matthay MA, Saint S. Subglottic secretion drainage for preventing ventilator-associated pneumonia: a meta-analysis, Am J Med 2005;118(1):11-8.

24. Muscedere J, Rewa O, McKechnie K, Jiang X, Laporta D, Heyland DK. Subglottic secretion drainage for the prevention of ventilatorassociated pneumonia: a systematic review and meta-analysis, Crit Care Med 2011;39(8):1985-91.

25. Wang F, Bo L, Tang L, Lou J, Wu Y, Chen F, Li J, Deng X. Subglottict secretion drainage for preventing ventilator-associated pneumonia: an updated meta-analysis of randomized controlled trials, J Trauma 2012;72(5):1276-85

26. Mujica-Lopez KI, Pearce MA, Narron KA, Perez J, Rubin BK. In vitro evaluation of endotracheal tubes with intrinsic suction. Chest 2010;138(4):863-9.

27. O'Neal PV, Munro CL, Grap MJ, Rausch SM. Subglottic secretion viscosity and evacuation efficiency. Biol Res Nurs 2007; 8(3):202-9.

28. Shah S, Fung K, Brim S, Rubin BK. An in vitro evaluation of the effectiveness of endotracheal suction catheters. Chest 2005;128(5):3699704.

29. Lorente L, Lecuona $M$, Jiménez A, Mora ML, Sierra A. Influence of an endotracheal tube with polyurethane cuff and subglottic secretion drainage on pneumonia. Am J Respir Crit Care Med 2007;176(11):1079-83.

30. Różańska A, Wałaszek M, Wolak Z, Bulanda M. Prolonged hospitalization of patients with hospital acquired pneumoniae in the intensive care unit - morbidity, mortality and costs of. Przegl Epidemiol 2016;70(3):449-61.

31. Wałaszek M, Kosiarska A, Gniadek A, Kołpa M, Wolak Z, Dobroś W Siadek J. The risk factors for hospital-acquired pneumonia in the Intensive Care Unit. Przegl Epidemiol 2016;70(1):15-20. 